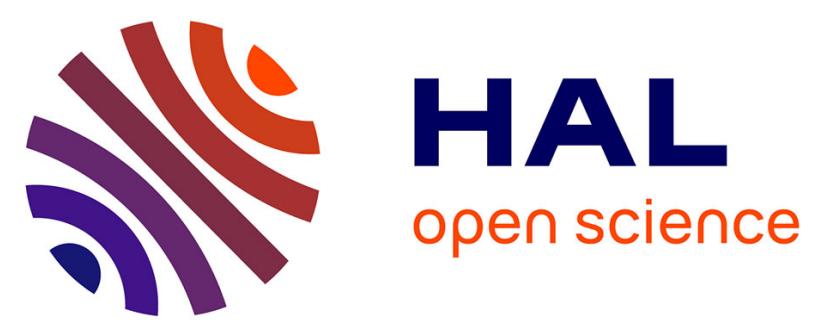

\title{
Economic Cycles and Their Synchronization: A Comparison of Cyclic Modes in Three European Countries
}

\author{
Lisa Sella, Gianna Vivaldo, Andreas Groth, Michael Ghil
}

\section{- To cite this version:}

Lisa Sella, Gianna Vivaldo, Andreas Groth, Michael Ghil. Economic Cycles and Their Synchronization: A Comparison of Cyclic Modes in Three European Countries. Journal of Business Cycle Research, 2016, 12 (1), pp.25 - 48. 10.1007/s41549-016-0003-4 . hal-01701122

\author{
HAL Id: hal-01701122 \\ https://hal.science/hal-01701122
}

Submitted on 5 Feb 2018

HAL is a multi-disciplinary open access archive for the deposit and dissemination of scientific research documents, whether they are published or not. The documents may come from teaching and research institutions in France or abroad, or from public or private research centers.
L'archive ouverte pluridisciplinaire HAL, est destinée au dépôt et à la diffusion de documents scientifiques de niveau recherche, publiés ou non, émanant des établissements d'enseignement et de recherche français ou étrangers, des laboratoires publics ou privés. 


\title{
Economic cycles and their synchronization: a comparison of cyclic modes in three European countries
}

\author{
Lisa Sella ${ }^{\mathrm{a}, \mathrm{b}, *}$, Gianna Vivaldo ${ }^{\mathrm{c}}$, Andreas Groth $^{\mathrm{d}, \mathrm{e}}$, Michael Ghil $^{\mathrm{d}, \mathrm{e}}$ \\ ${ }^{a}$ Department of Economics and Statistics "S. Cognetti de Martiis", University of Turin, \\ Italy \\ ${ }^{b}$ CNR-IRCrES, Moncalieri (Turin), Italy \\ ${ }^{c} I M T$ Institute for Advanced Studies, Lucca, Italy \\ ${ }^{d}$ Environmental Research 85 Teaching Institute and Geosciences Department, Ecole \\ Normale Supérieure, Paris, France \\ ${ }^{e}$ Department of Atmospheric $\&$ Oceanic Sciences and Institute of Geophysics $\&$ Planetary \\ Physics, University of California, Los Angeles, USA
}

\begin{abstract}
The present work applies singular spectrum analysis (SSA) to the study of macroeconomic fluctuations in three European countries: Italy, The Netherlands, and the United Kingdom. This advanced spectral method provides valuable spatial and frequency information for multivariate data sets and goes far beyond the classical forms of time domain analysis. In particular, SSA enables us to identify dominant cycles that characterize the deterministic behavior of each time series separately, as well as their shared behavior. We demonstrate its usefulness by analyzing several fundamental indicators of the three countries' real aggregate economy in a univariate, as well as a multivariate setting. Since business cycles are international phenomena, which show common characteristics across countries, our aim is to uncover supranational behavior within the set of representative European economies selected herein. Finally, the analysis is extended to include several indicators from the U.S. economy, in order to examine its influence on the European economies under study and their interrelationships.
\end{abstract}

Keywords: Advanced spectral methods, Business cycles, European Union, Frequency domain, Time domain

JEL classification: C15, C60, E32

\footnotetext{
${ }^{*}$ Corresponding author

Email addresses: lisa.sella@ircres.cnr.it (Lisa Sella), gianna.vivaldo@imtlucca.it (Gianna Vivaldo), andreasgroth@atmos.ucla.edu (Andreas Groth), ghil@lmd.ens.fr (Michael Ghil)
} 


\section{Introduction and motivation}

The nature of aggregate fluctuations is one of the most controversial topics in macroeconomics: the first systematic analysis of economic data from France, England, and the United States led Juglar (1862) to hypothesize a recurrent behavior of economic crises, with strong mutual dependence between their expansion and recession phases. About one-and-a-half centuries later, the debate on the nature and causes of economic fluctuations is still alive, and several fundamental issues - like the endogenous vs. the exogenous nature of business cycles and their propagation mechanisms - are still open (Kydland and Prescott, 1982; Long and Plosser, 1983; King and Rebelo, 2000; Chiarella et al., 2005; Hallegatte et al., 2008).

Although it is widely acknowledged that business cycles are multi-national phenomena, showing common characteristics across countries (Woitek, 1996; Dickerson et al., 1998; Den Haan and Sumner, 2001; Stock and Watson, 2005; Mazzi and Savio, 2006), there is still no agreement on basic issues like the quantification of comovements, the existence of supranational cycles (Graff, 2011) for instance at the European or G7 level-and the determinants of economic synchronization. For this reason, many theoretical and empirical studies disagree in their results, due to different data sets as well as different methodologies.

Concerning the mechanisms of economic synchronization, three main factors have been identified theoretically. First of all, some scholars argue that economic and capital integration supports the creation of specialized production structures, due to which sector-specific shocks become region-specific (Krugman, 1993; Kalemli-Ozcan et al., 2001). As a consequence, the business cycles of those countries that show similar production patterns would tend to converge (Imbs, 2004; Calderon et al., 2007); empirical studies (Otto et al., 2001; Baxter and Kouparitsas, 2005), however, are far from buttressing this hypothesis.

Other scholars direct their attention to trade barriers, arguing that their removal enhances synchronization, because of the consequent transmission of shocks in demand and because of knowledge and technological spillovers (Coe and Helpman, 1995; Frankel and Rose, 1998). Still, the effect of trade intensities on business cycle comovements is empirically not clear (Gruben et al., 2002; Calderon et al., 2007; Baxter and Kouparitsas, 2005).

Finally, the impact of monetary and financial integration on synchronization is theoretically ambiguous. On the one hand, monetary policies that are less asymmetric, exchange rates that are more stable, and stronger trading relations should have a positive impact on synchronization (Inklaar and De Haan, 2001; De Haan et al., 2002). On the other hand, fixed exchange rates could have a negative impact, since asymmetric shocks that may eventually occur cannot be absorbed by adjusting exchange rates and are discharged on the real economy (De Haan et al., 2008). It is clear, therewith, that considerable disagreement on the extent and nature of macroeconomic synchronization persists.

The present work attempts to shed further light on supranational synchronization of business cycles, by applying advanced spectral methods to a set of quarterly macroeconomic indicators across three European countries: Italy, The 
Netherlands, and the United Kingdom (henceforth UK). In the paper's last part, the indicators of the U.S. economy are added to the data set being analyzed, since this economy clearly affects the European ones and it is affected by them.

Given that economic time series are rather short, highly variable and often nonstationary, classical spectral estimation methods like the Fourier transform are limited in their ability to describe the underlying dynamical behavior (Granger and Hatanaka, 1964; Granger, 1966, 1969). New developments in spectral estimation techniques, however, have been shown to successfully overcome these limitations in many cases, and thus allow useful applications in various economic contexts (Lisi and Medio, 1997; Higo and Nakada, 1998; Atesoglu and Vilasuso, 1999; Baxter and King, 1999; A'Hearn and Woitek, 2001; Iacobucci, 2003; Christiano and Fitzgerald, 2003; Aadland, 2005; Wang, 2013; Pollock, 2014). Moreover, these advanced spectral methods support a richer description of multivariate phenomena than can be done by standard time-domain methods (Croux et al., 2001); this feature is particularly attractive in business cycle analysis.

In the present work we propose applying singular-spectrum analysis (SSA) to investigate multiple indicators, first in a univariate and, more importantly, in a multivariate setting. SSA is well suited for the analysis of short and noisy time series (Vautard et al., 1992; Ghil et al., 2002), like the typical macroeconomic ones. It is a nonparametric decomposition methodology and it does not require any a priori modeling of a time series to be analyzed. SSA allows a systematic description, quantification, and extraction of long-, medium-, and short-term components of the series being analyzed. Univariate SSA allows one to investigate the behavior of each indicator separately, extracting the dominant periodic and quasi-periodic oscillations that account for most of the series' variability. Recent applications of univariate SSA to macroeconomics include de Carvalho et al. (2012), Sella and Marchionatti (2012), and Dumas et al. (2014). Several practical aspects of SSA and its application to time series in general are covered in Golyandina et al. (2001) and Golyandina and Zhigljavsky (2013).

On the other hand, the extension to multivariate SSA (M-SSA) gives deeper insights into the common behavior of business fluctuations, both across countries and across indicators. M-SSA methodology, as presented in this paper, is quite innovative in the field of economic research and extends classical macroeconomic analysis in the time domain to the frequency domain. Although M-SSA has been applied extensively and successfully to many fields of research, cf.Ghil et al. (2002) and references therein, it has been apparently ignored in the analysis of socio-economic problems so far. Only recently Groth et al. (2012) have applied M-SSA to the study of U.S. business cycles in a completely multivariate fashion.

The paper is divided into six sections: In Section 2, we introduce the data set and the pre-processing procedure. In Section 3, we present the methodology of univariate analysis, its multivariate extension, and a crucial significance test. In Section 4, we apply the method to individual time series, and then discuss different combinations thereof in Section 5. Finally, we draw conclusions about the underlying macroeconomic dynamics and its synchronization in Section 6 . 


\section{Motivation and data selection}

\subsection{Sample selection of European countries}

Our analysis is based on quarterly national accounts from Italy, The Netherlands, and the UK. ${ }^{1}$ These three European economies have been selected because of their distinct characteristics in trade intensity, labor market structure, and access to energy resources. They are a small but illustrative sample of different potentialities in the complex integration mechanisms that characterize the evolving European context. The purpose of using such a small sample is to illustrate the usefulness of the proposed methodology, while still gaining at least preliminary insights into mutual synchronization dynamics. Future extension to the full EU-15 and even EU-28 framework is the ultimate goal, of course.

First of all, bilateral trade is a recognized channel for the propagation of international shocks; it affects, therefore, synchronization among different economic systems. Accordingly, these three countries show distinct trade structures and intensities. In particular, The Netherlands are a small and wide-open economy, showing relatively small GDP levels but very high shares of imports and exports. $^{2}$ Due to their higher trade intensity, they are more exposed to international shocks in comparison with Italy and the UK, two economies that are more closed. Moreover, the UK is most strongly linked to the U.S., while Italy's most important trading partner is Germany. ${ }^{3}$

A second important difference between the three countries in our sample concerns their labor market structure, which could significantly affect GDP fluctuations. In particular, the strong movements in the GDP residuals of the UK economy could be partially due to its flexible labor market. In fact, the low bargaining power of the trade unions that characterizes the post-Thatcher era allows more flexible adjustments in both wages and employment, thus determining more rapid responses to both positive and negative shocks, along with more sudden recessions and more pronounced expansions. On the contrary, the high bargaining power of the Italian trade unions is likely to cause a more robust reaction of the entire economic system. ${ }^{4}$ Finally, the Dutch economy shows an intermediate behavior between Italy and the UK, being characterized by a labor market structure close to the Scandinavian type (Esping-Andersen, 1999).

Finally, a third important factor that differentiates these three economies is the availability of energy resources, which can strongly affect their economic performance. While The Netherlands and the UK both have direct access to

\footnotetext{
${ }^{1}$ Quarterly national accounts are compiled according to the European System of Accounts (ESA95). Data are available from EUROSTAT at http://epp.eurostat.ec.europa.eu.

${ }^{2}$ In 2008 , the ratio of imports to GDP was around $28 \%$ for Italy, $34 \%$ for the UK, and $77 \%$ for The Netherlands. The exports were about $28 \%, 29 \%$, and $84 \%$ of GDP, respectively.

${ }^{3}$ In 2000, the UK exported to the U.S. $15.4 \%$ of its total exports and imported from it $13.2 \%$ of its total imports, while Italy exported $14.5 \%$ of its total to Germany and imported $17.7 \%$ from it, cf. Feenstra et al. (2005).

${ }^{4}$ For instance, Italian collective agreements involve very complex firing procedures for firms that have more than 15 workers. As a consequence, both medium- and large-size firms are strongly discouraged from modifying their employment level.
} 
natural energy sources, Italy is a strong net oil importer. Thus, energy supply shocks are likely to affect Italy much more strongly than the other two countries, and hence induce larger business fluctuations. As an example, zooming in on the trend of the Italian GDP in the 1970s and early 1980s illustrates how the 1973 and 1979 energy shocks lengthened the Italian recession phase in the early 1980s (not shown).

\subsection{Data set and pre-processing}

For each country, we analyze GDP at market prices, final consumption expenditure, gross fixed capital formation, exports, and imports of goods and services. ${ }^{5}$ The time series refer to the different time intervals of availability: they cover 54 years for the UK (1955:01-2008:04, $N=216)$, 32 years for the Netherlands (1977:01-2008:04, $N=128$ ), and 28 years for Italy (1981:01-2008:01, $N=112$ ); here $N$ stands for the number of quarters.

Figure 1 shows the raw time series and the corresponding trend. The trend has been estimated by the Hodrick-Prescott (HP) filter (Hodrick and Prescott, 1997), with the standard smoothing parameter for quarterly time series of $\lambda=$ 1600. For normalization purposes, the trend was extracted from the raw time series, the corresponding residuals were divided by the trend, and then the relative residuals were standardized to the same variance. Figure 2 illustrates this pre-processing procedure.

\section{Methodology}

\subsection{Singular spectrum analysis (SSA)}

Single-channel SSA and its multivariate extension (M-SSA) are non-parametric methods of time series analysis that provide insight into the unknown or partially known dynamics of the underlying dynamical system (Broomhead and King, 1986a,b; Vautard and Ghil, 1989; Ghil and Vautard, 1991; Vautard et al., 1992). SSA and M-SSA allow the identification of different components of the analyzed signal - such as trends and oscillatory patterns - without the explicit need of a parametric model.

The starting point of single-channel SSA is the Mañé-Takens idea to reconstruct dynamics from a single time series by its time-delayed embedding (Mañé, 1981; Takens, 1981), and then to find a new orthogonal basis for the extended phase space so obtained that describes most of the variance in the original time series by a minimal number of components. Broomhead and King (1986a) proposed the application of principal component analysis (PCA) to solve this optimization problem.

M-SSA is the extension of SSA to multivariate time series (Broomhead and King, 1986b; Keppenne and Ghil, 1993; Plaut and Vautard, 1994). It simultaneously analyses multiple channels in order to identify and extract dominant

\footnotetext{
${ }^{5}$ All series are expressed in constant year-2000 Euros. They are seasonally adjusted and corrected by working days, following the TRAMO-SEATS procedure (Maravall, 2005).
} 
spatio-temporal structures of the underlying dynamics. In particular, M-SSA helps to extract oscillatory patterns that are common to the time series at hand, even if they account for different fractions of variance in each of the time series.

Given an $L$-channel vector time series $\mathbf{x}(t)=\left\{x_{l}(t): l=1, \ldots, L ; t=1, \ldots, N\right\}$ of length $N$, its $L M \times L M$ grand covariance matrix $\mathbf{C}$ has the form

$$
\mathbf{C}=\left(\begin{array}{cccc}
\mathbf{C}_{1,1} & \mathbf{C}_{1,2} & \ldots & \mathbf{C}_{1, L} \\
\mathbf{C}_{2,1} & \mathbf{C}_{2,2} & \ldots & \mathbf{C}_{2, L} \\
\vdots & \vdots & \ddots & \vdots \\
\mathbf{C}_{L, 1} & \mathbf{C}_{L, 2} & \ldots & \mathbf{C}_{L, L}
\end{array}\right)
$$

Each block $\mathbf{C}_{l, l^{\prime}}$ is a covariance matrix between channels $l$ and $l^{\prime}$ and is estimated by

$$
\left(\mathbf{C}_{l, l^{\prime}}\right)_{i, j}=\frac{1}{\tilde{N}} \sum_{t=\min \{1,1+i-j\}}^{\max \{N, N+i-j\}} x_{l}(t) x_{l^{\prime}}(t+i-j),
$$

where $\tilde{N}=\min \{N, N+i-j\}-\max \{1,1+i-j\}+1$ depends on the range of summation. In case of single-channel SSA, $L=1$, the covariance matrix simplifies to an auto-covariance matrix, in which we have constant entries $c_{i j}$ along the (sub- and super)diagonals; i.e. the matrix has Toeplitz structure (Vautard and Ghil, 1989).

Next, the grand covariance matrix $\mathbf{C}$ is diagonalized

$$
\Lambda=\mathbf{E}^{\prime} \mathbf{C} \mathbf{E}
$$

to yield a diagonal matrix $\boldsymbol{\Lambda}$ of eigenvalues $\lambda_{k}$ and an orthogonal matrix $\mathbf{E}$ of eigenvectors. The columns $\mathbf{e}_{k}$ of $\mathbf{E}$ represent the new $L M$-dimensional coordinate system and $\lambda_{k}$ describes the variance of $\mathbf{X}$ in the direction of $\mathbf{e}_{k}$. Since the eigendecomposition in Eq. (3) is a similarity transformation of $\mathbf{C}$, the variance of the original time series $x(t)$ is preserved in the eigenvalues, which now lie along the main diagonal of $\boldsymbol{\Lambda}$.

From the largest eigenvalues we get a first impression of the most important part of the signal, which often can be separated from a tail of many small eigenvalues. Further, in order to identify periodic or quasi-periodic behavior in the original signal, Vautard and Ghil (1989) found that nearby eigenvalues at times form a pair, with their variances being nearly equal, while the corresponding eigenvectors have the same period and are in phase quadrature. These so-called 'oscillatory pairs' are the analog of sine-and-cosine pairs in Fourier analysis and adapt to the oscillations present in the system. However, in contrast to a classical Fourier decomposition, the new orthogonal basis is data adaptive and not restricted to pure sine and cosine functions. This way, SSA provides a reconstruction of a skeleton of the dynamical system's structure that is formed by a few robust periodic orbits.

M-SSA eigenvectors, on the other hand, describe temporal as well as spatial correlations of the multivariate data set, where the $L$-dimensional space here is that of the $L$-channel vector time series $\mathbf{x}(t)$. Each eigenvector $\mathbf{e}_{k}$ of length $L M$ 
consists of $L$ consecutive segments of length $M$, denoted by $\mathbf{e}_{k}=\left\{e_{k}^{l}(j): l=\right.$ $1 \ldots L ; j=1 \ldots M\}$. Each segment that is associated with an individual channel describes the participation of that channel in a particular oscillatory mode. This way, M-SSA goes beyond a pure univariate Fourier decomposition, and extends the idea of a spectral decomposition to high-dimensional multichannel time series.

By projecting the time series $x(t)$ onto each of the $L M$ eigenvectors $\mathbf{e}_{k}$, we get the principal components (PCs),

$$
a_{k}(t)=\sum_{l=1}^{L} \sum_{j=1}^{M} x_{l}(t+j-1) e_{k}^{l}(j),
$$

with $1 \leq t \leq N-M+1$. This projection yields $L M$ PCs of reduced length $N-M+1$. For this reason, PCs do not allow a unique localization in time.

We are able, however, to study various aspects of the time series that belong to the direction $\mathbf{e}_{k}$ by computing its reconstructed component (RC),

$$
r_{k}^{l}(t)=\frac{1}{M_{t}} \sum_{j=L_{t}}^{U_{t}} a_{k}(t-j+1) e_{k}^{l}(j),
$$

with $k=1, \ldots, L M$, and $\left(M_{t}, L_{t}, U_{t}\right)=(M, 1, M)$ for $M \leq t \leq N-M+1$; for either end interval they are given in Ghil et al. (2002). No information is lost during this reconstruction process, since the sum of all individual RCs, $x_{l}(t)=\sum_{k=1}^{L M} r_{k}^{l}(t)$, gives the original time series (Vautard et al., 1992).

\subsection{Monte Carlo SSA significance test}

A critical step in all forms of spectral analysis is to distinguish between significant oscillations and random fluctuations. The classical signal extraction approach, based on the identification of a gap in the spectrum of eigenvalues, has several limitations: when either the signal-to-noise ratio decreases or the random fluctuations correlate, a separation into a few large eigenvalues and a remaining noise floor becomes meaningless.

Allen and Smith (1996) have proposed, therefore, a more objective test, based on a Monte Carlo simulation technique. In this approach, the extracted spectral components are tested against a red-noise hypothesis, i.e. an autoregressive process of order $1, \operatorname{AR}(1)$,

$$
X(t)=a_{1}\left[X(t-1)-X_{0}\right]+\sigma \xi(t)+X_{0} ;
$$

here $X_{0}$ is the process mean and $\xi$ a normally distributed white-noise process with zero mean and unit variance.

Once the coefficients $a_{1}$ and $\sigma$ are estimated from the time series, an ensemble of surrogate time series is generated from the AR(1) process and compared with the real data. In practice, this requires one to estimate the covariance matrix $\mathbf{C}_{R}$ for each $\mathrm{AR}(1)$ realization and to project $\mathbf{C}_{R}$ onto the eigenvectors $\mathbf{E}$ of the original data

$$
\boldsymbol{\Lambda}_{R}=\mathbf{E}^{\prime} \mathbf{C}_{R} \mathbf{E} .
$$


Since Eq. (7) is not the eigendecomposition of the surrogate covariance matrix $\mathbf{C}_{R}$, the matrix $\boldsymbol{\Lambda}_{R}$ is not necessarily diagonal, as it is in Eq. (3). In fact, this projection allows one to determine the degree of resemblance between the surrogates generated by the test and the original data by computing statistics on the diagonal elements. From the ensemble distribution of $\lambda_{R}$ along the diagonal, we are able to obtain significance intervals outside which the time series' eigenvalues can be considered to be significantly different from an $\operatorname{AR}(1)$ process in Eq. (6). Note that a rejection of the most likely $\operatorname{AR}(1)$ process leads to a rejection of all other red-noise processes, at the same or at an even higher level of significance (Ghil et al., 2002).

In the case of a multivariate data set, we follow the approach of Allen and Robertson (1996), and transform the $L$ input channels to pairwise uncorrelated ones. This rotation can be simply achieved by a classical PCA, to which end we are able to test the invariant set of eigenvalues against $L$ independent $\operatorname{AR}(1)$ processes. This avoids the test against a vector $\mathrm{AR}(1)$ process, which may itself support oscillations, the so-called principal oscillation patterns, or POPs (Penland, 1989; Von Storch, 1995).

In the null hypothesis test, we have to consider the influence of the HP filter in the pre-processing procedure. To estimate the $\mathrm{AR}(1)$ parameter for the trend residuals, we follow the procedure of Groth et al. (2012) and choose the parameter $a$ such that the lag-1 covariance function of the HP filtered AR(1) output matches that of the trend residual. Given the model parameter $a$, we estimate $\sigma$ with the method proposed by Allen and Smith (1996), determine a set of surrogate realizations, and filter all realizations with exactly the same HP filter as the actual trend residuals. Finally, the filtered results are standardized to the same variance as the input channels. This way, the surrogate realizations and the trend residuals are pre-processed exactly the same way, and the null hypothesis cannot be simply rejected due to the detrending procedure, cf. Nelson and Kang (1981) and Cogley and Nason (1995), or due to a particular choice of the smoothing parameter $\lambda$.

\section{Individual analysis of macroeconomic indicators}

In this section, we perform a univariate SSA analysis of all the indicators discussed in Section 2. To do so, we use the pre-processed data shown in Fig. 2 and the SSA-MTM spectral toolkit developed at UCLA, which is available as freeware at http://www. atmos.ucla.edu/tcd/ssa/.

The pre-processing is of the essence for the spectral analysis, since raw economic variables are typically characterized by a pervasive trend that dominates the shape of the power spectral estimate. This trend dominance is reflected in a high peak at zero frequency, which is scattered into the neighboring frequency bands due to leakage effects (Granger, 1966); Fig. 3a illustrates this effect on the GDP of the UK. After removing the trend with the help of the HP filter, the power spectral density (PSD) estimates in Fig. 3b reveal three distinct peaks, associated with periodicities at about 9,5 , and 3 years. These spectral peaks 
suggest the presence of roughly periodic components in the analyzed series, whose robustness remains to be confirmed by further statistical tests.

In contrast to our two-step approach, de Carvalho et al. (2012) have chosen to apply a single SSA analysis for the decomposition of a macroeconomic time series into trend and fluctuations. Although such an approach provides a consistent separation into an overall trend component and transitory fluctuations that are orthogonal to it at zero lag, the trend is likely to dominate the SSA's variancebased decomposition and small fluctuations will then be masked; this is indeed the case for the PSD estimate of raw UK GDP data shown in Fig. 3a.

In the next step, we carry out an SSA analysis of the trend residuals of the UK GDP. Figure 4 shows the spectrum of eigenvalues (filled circles) assigned to a frequency scale on the abscissa ${ }^{6}$.

The error bars represent the $2.5 \%$ and $97.5 \%$ quantiles of variance from an ensemble of 1000 red noise realizations (cf. Section 3.2). Hence, it is very unlikely that the eigenvalues lying outside the corresponding error bars are consistent with the hypothesis of random fluctuations generated by a red-noise process. In the case of the UK GDP, the eigenvalues 1-2 and 3-4 (filled circles) have more power than can be explained by simple red noise. The near-equality of the two eigenvalues in each of these two pairs - in their size, as well as in the frequency of the associated eigenmodes - suggests further that they represent oscillatory pairs (Ghil et al., 2002).

Figure 4 indicates that the eigenvalue pair 1-2 is associated with a frequency of approximately 5 years, which captures $39 \%$ of the variance in the detrended and normalized time series. The pair 3-4 can be attributed to a 9 -year oscillation, which describes $23 \%$ of the variance. Hence, almost two-thirds of the variance is associated with the first four PCs of our SSA analysis. A possible 3 -year oscillation in the PSD estimation of Fig. 3 can be identified with the eigenvalue pair 7-8, but Fig. 4 shows that it cannot be distinguished from an AR(1) process at the $95 \%$ confidence level. Finally, note the oscillatory pair at a 1-year periodicity, which clearly lies below the expected variance level. This can be attributed to the elimination of the seasonal behavior in our pre-processing (cf. Section 2).

This comparison between the classical PSD estimation of Fig. 3 and the SSA estimates in Fig. 4 illustrates the capability of SSA to automatically identify oscillations and to capture the statistically significant dynamical behavior by using just a few components. This parsimonious description of the time series by SSA substantially simplifies the comparison of multiple indicators. On each time series of the data set, we perform a separate SSA analysis, identifying oscillatory pairs, and testing for their significance by means of Monte Carlo SSA. Table 1 summarizes the findings for each indicator within each country,

\footnotetext{
${ }^{6}$ Plotting the eigenvalues against their rank, as originally proposed by Vautard and Ghil (1989), is more useful in distinguishing between signal and noise. In identifying and statistically testing for oscillatory modes, as we do here, it is more informative to plot the eigenvalues versus the associated frequency of the corresponding eigenvectors (cf. Allen and Smith, 1996).
} 
Table 1: Univariate SSA analysis. Oscillations significant at the $95 \%$ level are indicated by filled circles, with their partial variances in parentheses; open circles indicate the presence of oscillations at a lower significance level.

\begin{tabular}{|c|c|c|c|}
\hline & 9 yrs & 5 yrs & 3 yrs \\
\hline \multicolumn{4}{|c|}{ UK } \\
\hline GDP & - $(23 \%)$ & - $(39 \%)$ & $\circ(7 \%)$ \\
\hline Consumption & & - $(22 \%)$ & $\circ(4 \%)$ \\
\hline Fixed investments & & - $(35 \%)$ & $\circ(7 \%)$ \\
\hline Exports & & - $(18 \%)$ & - $(15 \%)$ \\
\hline Imports & & - $(25 \%)$ & \\
\hline \multicolumn{4}{|c|}{ The Netherlands } \\
\hline GDP & & - $(44 \%)$ & \\
\hline Consumption & $\circ(48 \%)$ & & $\circ(3 \%)$ \\
\hline Fixed investments & - $(33 \%)$ & & \\
\hline Exports & & - $(38 \%)$ & - $(9 \%)$ \\
\hline Imports & & - $(39 \%)$ & $\circ(9 \%)$ \\
\hline \multicolumn{4}{|c|}{ Italy } \\
\hline GDP & & - $(40 \%)$ & $\circ(20 \%)$ \\
\hline Consumption & - $(59 \%)$ & & - $(13 \%)$ \\
\hline Fixed investments & & $\circ(25 \%)$ & $\circ(6 \%)$ \\
\hline Exports & & - $(45 \%)$ & - $(16 \%)$ \\
\hline Imports & & $\circ(17 \%)$ & - $(29 \%)$ \\
\hline TOTAL FINDINGS & $4 / 15$ & $12 / 15$ & $12 / 15$ \\
\hline
\end{tabular}

where filled circles indicate oscillations that are significant at a $95 \%$ confidence level, while open circles indicate that an oscillatory pair is present, but at a lower confidence level.

The results in Table 1 suggest a remarkable homogeneity in cyclical behavior among the indicators of Italy, the UK, and the Netherlands. Despite the different structures of each country's economic system and the different observational spans, the complex picture of the macroeconomic indicators can be reduced to three components:

- a long-term mode of about 9 years, in a few times series;

- an intermediate 5-year oscillation, in nearly all indicators; and

- a faster oscillation of about 3 years, accounting for a small fraction of the total variance.

As already mentioned at the beginning of Section 3, a few robust periodic orbits can generate phase- and amplitude-modulated oscillations in the observed time series. This behavior can be reconstructed, to some extent, by using the RCs. As an example, in Fig. 5 we reconstruct the 5 -year oscillation in the GDP of the three countries. All the patterns in Figs. 5(a,b,c) are significant against a red-noise hypothesis and represent a large fraction of the GDP variance. 
The reconstruction of the UK GDP describes an increase in the amplitude of this 5-year mode due to huge energetic shocks in 1973 and 1979. The reconstruction of Italian GDP shows the lengthening of the recession phase and the following stretched recovery in the early 1980s due to energy shocks, the subsequent counter-shock and the dollar depreciation. The 5-year oscillation in exports, however, is much more weakly modulated, thus suggesting a stabler behavior (not shown).

The 9-year oscillation is less significant in our fairly short data set ${ }^{7}$. In all the UK indicators, some pairing of the corresponding eigenelements emerges, but this oscillatory pair is unambiguously significant only in the case of the GDP. Again, the reconstruction of this mode exhibits an increase in amplitude from the late 1970s to the early '90s (not shown).

Finally, the 3-year oscillation is generally less pronounced in the UK and The Netherlands; its partial variance there lies in the range of $3 \%-15 \%$. On the contrary, its role is significant in all Italian series, particularly in imports and the GDP, as the following multivariate analysis shows; see Section 5.1.

These results are quite consistent with those of several previous studies in finding similar oscillatory behavior in multiple macroeconomic indicators. The classical pioneering works of Juglar (1862) and Kitchin (1923) identified fairly regular 7-10-year fluctuations in financial series - related in fine to investments in equipment-and 3-4-year fluctuations in output series that are due to inventories, respectively.

Many recent studies have confirmed the presence of similar periodicities in univariate as well as multivariate macroeconomic series. For instance, Woitek (1996) found both the classical multi-year "Juglar" and the shorter "Kitchin" periodicities in G7 GDPs, while A'Hearn and Woitek (2001) detected similar periodicities in the industrial production data of 13 North Atlantic and peripheral countries during the 20th century. Likewise, Sussmuth (2002) obtained analogous results by analyzing the 20th-century aggregates of national income and product accounts (NIPA) for the central G7 and Euro15 countries.

\section{Composite analysis of multiple indicators}

In the previous section, we have focused on separate SSA analyses of individual indicators for single countries, and found a remarkable agreement in their spectral properties. This striking simplicity in the rather complex picture of economic behavior for three very diverse European countries remains to be verified by a composite analysis of multiple indicators and countries. The detection of similar oscillatory patterns across the univariate series points to the presence of similar dynamics, but it does not suffice in order to draw conclusions about their coupling. The inclusion of cross-correlations into the analysis of business cycles, though, will help draw such conclusions.

\footnotetext{
${ }^{7}$ Note that the chance of not being significant increases with the period length.
} 
Table 2: Country-based M-SSA results. Oscillations significant at the 95\% level are marked as filled circles.

\begin{tabular}{c|c|c|c}
\hline \hline & 9 yrs & 5 yrs & 3 yrs \\
\hline UK & $\bullet$ & $\bullet$ & \\
The Netherlands & & $\bullet$ & $\bullet$ \\
Italy & & $\bullet$ & $\bullet$ \\
\hline
\end{tabular}

In practice, including the cross-correlations into the analysis requires one to combine multiple macroeconomic indicators into a single M-SSA. We consider herewith two different configurations: we combine (1) all indicators from a single country and (2) all available indicators from all countries into a single M-SSA analysis. We refer to the two configurations as the "country-based" and "global" analyses, respectively. This hierarchy of configurations allows us to gradually investigate the existence of cyclic, oscillatory modes from smaller to larger scales, and to identify phenomena on a local as well as on a regional scale.

This hierarchical approach helps in particular to avoid an increase in the number of false positive detections (type II error) in the significance analysis of the eigenvalues: with an increasing number of channels and a decreasing length of observations, discrepancies between the null-hypothesis model and the data at hand become more likely. For this reason, we focus in the following M-SSA analysis only on those oscillations that have already been identified in the univariate SSA (see Table 1).

\subsection{Country-based analysis}

In this section, we combine all economic indicators for each country into a single M-SSA analysis. Doing so allows one to understand specific, country-level dynamics. The most highly significant oscillations are summarized in Table 2. As in the univariate analyses, the 5-year oscillation is clearly shared by all three countries, while the highest frequencies are well established in the Italian macroeconomic time series, and the 9-year component prevails in the UK.

These similar periodicities are an evidence of common features in the dynamics of industrialized economies (Blanchard and Watson, 1984; Stanca, 1999; Stock and Watson, 2002, 2005). Consequently, many authors have looked for the existence of common, supranational or international cycles, and for the corresponding transmission mechanisms, by analyzing macroeconomic co-movements and their causes. Thus, Kose et al. (2003) have used a Bayesian dynamic factor model to analyze a 60-country sample of three economic aggregates from seven regions - North America, Europe, Oceania, Latin America, Africa, and Asia (developing and developed) - and found that a common "world factor" plays a more important role than region-specific factors in these 180 time series.

Based on a time-varying weighting matrix, Lumsdaine and Prasad (2003) found evidence for a "world business cycle," as well as for a common component of European countries. On the other hand, Artis (2003) applied a band-pass version of the HP filter and hierarchical cluster analysis to 23 OECD countries, 
of which 15 were European; given the fairly short time span, of 30 years, covered by this author's dataset - and the use of a band-pass filter that is somewhat less effective than our advanced version of M-SSA - his results on the existence of a "European cycle" were somewhat inconclusive.

The above-mentioned time series analyses were conducted with no particular connection to the arguments about the causal mechanisms of the cycles, endogenous or exogenous, as discussed at the beginning of the Introduction to this paper. But the intuition of commonality among the various European economies is further strengthened by the remarkable correspondence between our empirical findings and the theoretical predictions of the non-equilibrium dynamic model (NEDyM) of Hallegatte et al. (2008). NEDyM is a highly simplified macroeconomic model that introduces investment dynamics and non-equilibrium effects into a Solow (1956) growth model. Its equilibrium state matches the EU-15 statistics for 2001, cf. Eurostat (2002) and Table 4 in Hallegatte et al. (2008).

NEDyM exhibits endogenous business cycles of 5-6 years in duration about this equilibrium state, as well as near-annual fluctuations. The 5-6-year periodicity emerges in profits, production, and employment, consistently with the well-known mean business cycle period (Zarnowitz, 1985; King and Watson, 1996; Kontolemis, 1997) and with the strongest and most robust common periodicity obtained in the present analysis. In addition, NEDyM exhibits the characteristic seesaw shape of business cycles, with short recessions and substantially longer recoveries, as well as several stylized facts of the business cycle in terms of lead-lag relationships between indicators.

The chaotic nature of NEDyM solutions for realistic model parameter values raises the possibility of synchronization between individual national economiesif each were governed by a NEDyM-type oscillator with slightly different parameter values - according to well-known principles of the dynamics of chaotic oscillators (Pikovsky et al., 2003). The detailed numerical calibration of NEDyM to the actual history of macroeconomic indicators of several major economies - in Europe and elsewhere - is still necessary in order to pursue this novel avenue (Groth et al., 2015a), and has to be left for future work.

\subsection{Global analysis}

In this subsection we combine all given time series into a single M-SSA analysis and focus on the dynamics that dominate the economic behavior on the broadest scale covered by our data sets. Since Groth et al. (2012, 2015b) have already discussed the presence of a 5-year oscillatory mode in the U.S. economy, we extend here the analysis to the U.S. economy. Doing so will allow us to assess possible links between oscillatory modes in the economies of the European Union and of the U.S.

The quarterly data set for the U.S. macroeconomic indicators is provided by the Bureau of Economic Analysis (BEA; see http://www.bea.gov) and all

monetary variables are in constant 2005 dollars. Like for the European data, we first non-dimensionalize the trend residuals by dividing them by the long-term trend, and then standardize the relative residuals. 
Recall that the individual SSA and M-SSA analyses of the three EU countries found, in most cases, three oscillatory pairs with periods of approximately 9,5 , and 3 years, respectively; see again Tables 1 and 2. The eigenvalue spectrum in Fig. 6 clearly shows three oscillatory pairs, each significant above the $95 \%$ level, with the the same periodicities. The sum of the variances captured by these three pairs is $27+19+7=53 \%$ of the variance in the total data set of (five indicators $) \times$ (four countries), including now the U.S.

The longest period of 9 years is just barely significant at the $95 \%$ level, confirming the finding that this oscillation is hard to detect in the individual time series taken separately, one-by-one (Table 1). It is especially the short overlap in time span, from 1981 to 2008, in this global M-SSA analysis that complicates the distinction between random fluctuations and deterministic oscillations at this period length.

On the other hand, the 5- and 3-year oscillations can be identified more often in the single-channel SSA and the corresponding eigenvalues in Fig. 6 rise well above the $95 \%$ level of significance. Hence, it is highly unlikely that these cyclic modes can be attributed to random fluctuations, even in the barely three decades of data available at this time.

Next, we reconstruct the temporal behavior that corresponds to these three oscillatory pairs. The reconstruction with a few RCs allows a streamlined view of the rather complex behavior of multiple countries and their indicators. It thus helps separate common behavior from single shocks. As a consequence, the behavior seen in Fig. 7 is indeed rather homogeneous across all four countries and their five indicators .

It is quite remarkable that the U.S. economy reveals the most coherent within-country behavior over the whole interval of observation (Fig. 7(d)), and that all its indicators behave quite similarly, in both amplitude and phase. For the three EU countries, the amplitude modulation in time is still fairly consistent for each country separately, but the phases are more variable, from indicator to indicator for the same country as well as across countries.

The UK is fairly strongly linked to the U.S. during the '90s (Fig. 7(a)), but it shows a more erratic behavior recently, probably due to its stronger European integration in the last two decades. On the other hand, The Netherlands and Italy are generally more closely linked over the entire data span, and their macroeconomic behavior is quite similar. In the '90s, both countries clearly lag behind the U.S. and the UK, while in recent times this delay has been reduced.

Finally, to quantify the participation of each country and of its indicators in the three global oscillatory modes, we analyze the variance of the corresponding RCs for each time series separately (Fig. 8). The 9-yr oscillatory mode is the strongest in the European countries, where it clearly dominates consumption. In the U.S. market, the importance of this mode is clearly quite limited, except for the exports. This match between EU consumption and U.S. exports points to an obvious link between the two markets.

The second oscillatory mode, with a period length of five years, has quite a different behavior from one country to another. In the case of the UK, this mode has nearly the same energy for all aggregates, whereas for the Netherlands 
and Italy, the energy varies substantially from one indicator to another. This difference is in particular interesting insofar as the U.S. economy is concerned, since the business cycle there is dominated by a 5-year oscillatory mode (Groth et al., 2012). In this context, Fig. 8 supports a closer connection of the UK as a whole to the U.S. economy.

For the Netherlands and Italy, the picture is more complex since both countries are known to be more strongly linked to the European market. The consumption, for example, in both these countries shows a much weaker contribution of the 5 -year oscillations, although their stronger participation in the exports supports a link to the U.S. market.

The third pair, with a period length of three years, exhibits overall smaller variance, in agreement with the univariate SSA analyses. The picture for the 3 -year mode in Fig. 8 is less informative and we are not able to associate this mode either to any particular country or to a particular indicator. Other market mechanisms that we have not taken into account in the present analysis may play a role and it would be certainly of interest to extend the analysis to several additional countries with sufficiently long macroeconomic records.

\section{Summary and concluding remarks}

In this paper, we have carried out a frequency- and time-domain analysis of macroeconomic fluctuations in three European countries, namely Italy, The Netherlands, and the United Kingdom (UK). For each country, five fundamental indicators of the real aggregate economy - GDP, consumption, fixed investments, exports and imports - have been considered in order to describe several aspects of the economic behavior of these countries, separately as well as together. Despite the peculiarities of each individual economy, the results obtained from both uni- and multivariate investigations by singular spectrum analysis (SSA) suggest the presence of quite a homogeneous multi-cyclical behavior among the countries and indicators.

We have demonstrated that multivariate SSA (M-SSA) clearly goes beyond a simple analysis of cross-correlations and offers the reconstruction of a robust "skeleton" of the underlying dynamics. In this context, M-SSA helps identify different market mechanisms, with their distinct characteristic time scales, and reduce the complex behavior of the system to a few robust oscillatory modes.

Such modes have been attributed, in other contexts, to the existence of weakly unstable periodic orbits in the system's phase space (Ghil et al., 2002). Albeit unstable, this type of closed orbits, also called limit cycles in dynamical systems theory, influence the system's behavior and play an important

role in the synchronization process between the irregular evolutions of several macroeconomic indicators within a country and between the economies of several countries. Hence, these orbits leave their imprint in the economic system's trajectories - i.e. in the observed time series of indicators - and it is of special interest to identify and reconstruct them for a set of different indicators and countries. 
In the present work, we have identified three main oscillatory modes in the macroeconomic evolution of these three EU countries: (a) a low-frequency oscillation of about 9 years, which is statistically significant at the $95 \%$ level only in some of the time series in our data sets; (b) a 5-year oscillation that is clearly dominant in all three countries; and (c) a 3-year oscillation, which shows less energy and is especially present in Italy and The Netherlands. Our analysis has further been extended to the U.S. economy and, in agreement with the findings of Groth et al. (2012, 2015b), the pervasive character of the 5-year oscillatory mode in the EU countries we had analyzed could indeed be attributed to its prevalence in the U.S. economy.

Finally, the statistical results in this paper tentatively support the predictions made by the highly idealized NEDyM model of Hallegatte et al. (2008), namely the presence of an endogenous business cycle with a period of roughly 5-6 years. The model's 5-6-year periodicity is shared by all the indicators examined here, and it is consistent with the mean business cycle period found by several authors (Zarnowitz, 1985; King and Watson, 1996; Kontolemis, 1997).

This preliminary agreement between NEDyM and the time-series analyses herein is quite encouraging. Moreover, the chaotic character of NEDyM solutions for reasonable parameter values suggests a synchronization mechanism between several industrialized economies as chaotic oscillators with slightly detuned parameter values (Pikovsky et al., 2003; Groth and Ghil, 2011). Further detailed numerical calibration of NEDyM to the actual history of macroeconomic indicators of major economies is necessary, though, in order to consolidate our confidence in the model's predictive power.

To conclude, M-SSA provides a self-consistent and robust way of analyzing spatio-temporal behavior across countries and economic aggregates, where space is understood here in the sense of the phase space of the aggregates. This conclusion is especially in line with the U.S. National Bureau of Economic Research (NBER) understanding of business cycles, namely that a recession is a significant decline in economic activity spread across the economy, i.e. not one that is limited to GDP alone. In a multivariate framework, we have shown that the inclusion of more and more time series into M-SSA gives consistent results and helps extract oscillatory modes that are shared across different economies.

In future work, it is certainly of interest to extend the present analyses to several additional countries with sufficiently long aggregate records. Doing so would enable one to study shared mechanisms and synchronization effects on a global market.

\section{Acknowledgments}

We would like to thank Pietro Terna and Vittorio Valli for their valuable guidance to the two lead authors and for their many suggestions about the economic interpretation of this work's results. AG acknowledges support from the Groupement d'Intérêt Scientifique (GIS) Réseau de Recherche sur le Développement Soutenable (R2DS) of the Région Ile-de-France while affiliated with the Environmental Research and Teaching Institute at the Ecole Normale 
Supérieure in Paris. AG and MG both received support from NSF grant OCE1243175, as well as from ONR MURI grant N00014-12-1-0911. 


\section{References}

Aadland, D., 2005. Detrending time-aggregated data. Economic Letters 89, 28793.

A'Hearn, B., Woitek, U., 2001. More international evidence on the historical properties of business cycles. Journal of Monetary Economics 47, 321-46.

Allen, M., Robertson, A., 1996. Distinguishing modulated oscillations from coloured noise in multivariate datasets. Climate Dynamics 12, 775-784.

Allen, M. R., Smith, L. A., 1996. Monte Carlo SSA: detecting irregular oscillations in the presence of colored noise. Journal of Climate 9, 3373-3404.

Artis, M. J., 2003. Is there a European business cycle? Working Paper 1053, CESifo Group Munich.

Atesoglu, H. S., Vilasuso, J., 1999. A band spectral analysis of exports and economic growth in the United States. Review of International Economics 7, $140-152$.

Baxter, M., King, R. G., 1999. Measuring business cycles: approximate bandpass filters for economic time series. Review of Economics and Statistics 81, $575-593$.

Baxter, M., Kouparitsas, M. A., 2005. Determinants of business cycle movement: a robust analysis. Journal of Monetary Economics 52, 113-57.

Blackman, R. B., Tukey, J. W., 1958. The measurement of power spectra from the point of view of communication engineering. Dover Publications.

Blanchard, O. J., Watson, M. W., 1984. Are business cycles all alike? Working Paper w1392, National Bureau of Economic Research.

Broomhead, D. S., King, G., 1986a. Extracting qualitative dynamics from experimental data. Physica D 20, 217-36.

Broomhead, D. S., King, G. P., 1986b. On the qualitative analysis of experimental dynamical systems. In: Sarkar, S. (Ed.), Nonlinear Phenomena and Chaos. Adam Hilger, Bristol, England, pp. 113-144.

Calderon, C., Chong, A., Stein, E., 2007. Trade intensity and business cycle synchronization: Are developing countries any different? Journal of International Economics 71 (1), 2-21.

Chiarella, C., Flaschel, P., Franke, R., 2005. Foundations for a Disequilibrium Theory of the Business Cycle: Qualitative Analysis and Quantitative Assessment. Cambridge University Press.

Christiano, L. J., Fitzgerald, T. J., 2003. The band pass filter. International Economic Review 44 (2), 435-465. 
Coe, D., Helpman, E., 1995. International R\&D spillovers. European Economic Review 39 (7), 859-87.

Cogley, T., Nason, J. M., 1995. Effects of the Hodrick-Prescott filter on trend and difference stationary time series: Implications for business cycle research. Journal of Economic Dynamics and Control 19 (1-2), 253-278.

Croux, C., Forni, M., Reichlin, L., 2001. A measure of comovement for economic variables: theory and empirics. Review of Economics and Statistics 83 (2), $232-41$.

de Carvalho, M., Rodrigues, P. C., Rua, A., Jan. 2012. Tracking the US business cycle with a singular spectrum analysis. Economics Letters 114 (1), 32-35.

De Haan, J., Inklaar, R., Jong-A-Pin, R., 2008. Will business cycles in the Euro area converge? A critical survey of empirical research. Journal of Economic Surveys 22 (2), 234-273.

De Haan, J., Inklaar, R., Sleijpen, O., 2002. Have business cycles become more synchronized? Journal of Common Market Studies 40 (1), 23-42.

Den Haan, W. J., Sumner, S., 2001. The comovement between real activity and prices in the G7. Working Paper 8195, National Bureau of Economic Research.

Dickerson, A., Gibson, H., Tsakalotos, E., 1998. Business cycle correspondence in the European Union. Empirica 25 (1), 51-77.

Dumas, P., Ghil, M., Groth, A., Hallegatte, S., 2014. Dynamic coupling of the climate and macroeconomic systems. Mathematics of the Social Sciences, in press.

Esping-Andersen, G., 1999. Social Foundations of Postindustrial Economies. Oxford University.

Eurostat, 2002. Economic Portrait of the European Union 2001. Panorama of the European Union. European Commission.

Feenstra, R. C., Lipsey, R. E., Deng, H., Ma, A. C., Mo, H., 2005. World trade flows: 1962-2000. Working Paper 11040, National Bureau of Economic Research.

Frankel, J. A., Rose, A. K., 1998. The endogeneity of the optimum currency area criteria. Economic Journal 25, 1009-25.

Ghil, M., Allen, M. R., Dettinger, M. D., Ide, K., Kondrashov, D., Mann, M. E., Robertson, A. W., Saunders, A., Tian, Y., Varadi, F., Yiou, P., 2002. Advanced spectral methods for climatic time series. Reviews of Geophysics $40(1), 1-41$. 
Ghil, M., Vautard, R., 1991. Interdecadal oscillations and the warming trend in global temperature time series. Nature 350, 324-27.

Golyandina, N., Nekrutkin, V., Zhigliavsky, A., 2001. Analysis of time series structure: SSA and related techniques. Chapman \& Hall/CRC.

Golyandina, N., Zhigljavsky, A. A., 2013. Singular Spectrum Analysis for Time Series. Springer Berlin Heidelberg.

Graff, M., 2011. International business cycles: How do they relate to Switzerland? Tech. Rep. 291, KOF Swiss Economic Institute, ETH Zurich Working Paper.

Granger, C. W., 1966. The typical spectral shape of an economic variable. Econometrica 34 (1), 150-161.

Granger, C. W., 1969. Investigating causal relations by econometric models and cross-spectral methods 37 (3), 424-438.

Granger, C. W. J., Hatanaka, M., 1964. Spectral Analysis of Economic Time Series. Princeton Univ. Press.

Groth, A., Dumas, P., Ghil, M., Hallegatte, S., 2015a. Impacts of natural disasters on a dynamic economy. In: Chavez, E., Ghil, M., Urrutia-Fucugauchi, J. (Eds.), Extreme Events : Observations, Modeling, and Economics. American Geophysical Union and Wiley-Blackwell, p. 438.

Groth, A., Ghil, M., Sep. 2011. Multivariate singular spectrum analysis and the road to phase synchronization. Physical Review E 84, 036206.

Groth, A., Ghil, M., Hallegatte, S., Dumas, P., 2012. The role of oscillatory modes in U.S. business cycles. Working Paper 26, Fondazione Eni Enrico Mattei (FEEM).

Groth, A., Ghil, M., Hallegatte, S., Dumas, P., 2015b. The role of oscillatory modes in U.S. business cycles. OECD Journal: Journal of Business Cycle Measurement and Analysis 2015 (1), 63-81.

Gruben, W., Koo, J., Millis, 2002. How much does international trade affect business cycles synchronization? Working Paper 0203, Federal Reserve Bank of Dallas.

Hallegatte, S., Ghil, M., Dumas, P., Hourcade, J., 2008. Business cycles, bifurcations and chaos in neo-classical model with investment dynamics. Journal of Economic Behaviour and Organization 67, 57-77.

Higo, M., Nakada, S. K., 1998. How can we extract a fundamental trend from an economic time-series? Monetary and Economic Studies 16 (2), 61-111.

Hodrick, R. J., Prescott, E. C., 1997. Postwar U.S. business cycles: An empirical investigation. Journal of Money, Credit and Banking 29 (1), 1-16. 
Iacobucci, A., 2003. Spectral analysis for economic time series. Working Papers 07 , OFCE.

Imbs, J., 2004. Trade, finance, specialization, and synchronization. Review of Economics and Statistics 86 (3), 723-734.

Inklaar, R., De Haan, J., 2001. Is there really a European business cycle? A comment. Oxford Economic Review 53, 215-220.

Juglar, C., 1862. Des crises commerciales et de leur retour périodique, en France, en Angleterre et aux États Unis. Alcan, Paris.

Kalemli-Ozcan, S., Sørensen, B., Yosha, O., 2001. Economic integration, industrial specialization, and the asymmetry of macroeconomic fluctuations. Journal of International Economics 55 (1), 107-137.

Keppenne, C. L., Ghil, M., 1993. Adaptive filtering and prediction of noisy multivariate signals: An application to subannual variability in atmospheric angular momentum. International Journal of Bifurcation and Chaos 3, 625634 .

King, R., Rebelo, S., 2000. Resuscitating real business cycles. Working Paper 7534, National Bureau of Economic Research.

King, R., Watson, M., 1996. Money, prices, interest rates and the business cycles. Review of Economics and Statistics 78, 35-53.

Kitchin, J., 1923. Cycles and trends in economic factors. The Review of Economic Statistics 5, 10-16.

Kontolemis, Z., 1997. Does growth vary over the business cycle? Some evidence from the G7 countries. Economica 64, 441-60.

Kose, M. A., Otrok, C., Whiteman, C. H., 2003. International business cycles: World, region, and country-specific factors. American Economic Review, 1216-1239.

Krugman, P., 1993. Lessons of Massachusetts for EMU. In: Giavazzi, F. \& Torres, G. (Ed.), The Transition to Economic and Monetary Union. New York: Cambridge University Press, pp. 41-61.

Kydland, F. E., Prescott, E. C., 1982. Time to build and aggregate fluctuations. Econometrica 50 (6), 1345-1370.

Lisi, F., Medio, A., 1997. Is a random walk the best exchange rate predictor? International Journal of Forecasting 13, 255-67.

Long, Jr., J. B., Plosser, C., 1983. Real business cycles. The Journal of Political Economy 91 (1), 39-69. 
Lumsdaine, R. L., Prasad, E. S., 2003. Identifying the common component of international economic fluctuations: A new approach. The Economic Journal 113 (484), 101-127.

Mañé, R., 1981. On the dimension of the compact invariant sets of certain nonlinear maps. In: Dynamical Systems and Turbulence. Vol. 898 of Lecture Notes in Mathematics. Springer, Berlin, pp. 230-242.

Maravall, A., 2005. An application of the TRAMO-SEATS automatic procedure; direct versus indirect adjustment. Working Paper 0524, Bank of Spain.

Mazzi, G., Savio, G. (Eds.), 2006. Growth and Cycle in the Euro-Zone. Palgrave McMillan.

Nelson, C. R., Kang, H., 1981. Spurious periodicity in inappropriately detrended time series. Econometrica 49 (3), 741-751.

Otto, G., Voss, G., Willard, L., 2001. Understanding OECD output correlations. Economic Research Dept., Reserve Bank of Australia.

Penland, C., 1989. Random forcing and forecasting using principal oscillation pattern analysis. Monthly Weather Review 117, 2165-2185.

Pikovsky, A., Rosenblum, M., Kurths, J., 2003. Synchronization: A Universal Concept in Nonlinear Science. Cambridge University Press.

Plaut, G., Vautard, R., 1994. Spells of low-frequency oscillations and weather regimes in the Northern Hemisphere. Journal of the Atmospheric Sciences $51(2), 210-236$.

Pollock, D., 2014. Cycles, syllogisms and semantics: Examining the idea of spurious cycles. Journal of Time Series Econometrics 6 (1), 81-102.

Sella, L., Marchionatti, R., 2012. On the cyclical variability of economic growth in Italy, 1881-1913: a critical note. Cliometrica, 1-22.

Solow, R., 1956. A contribution to the theory of economic growth. The Quarterly Journal of Economics 70, 6594.

Stanca, L. M., 1999. Are business cycles all alike? Evidence from long-run international data. Applied Economics Letters 6, 765-69.

Stock, J. H., Watson, M. W., 2002. Has the business cycle changed and why? Macroeconomic Annual, National Bureau of Economic Research.

Stock, J. H., Watson, M. W., 2005. Understanding changes in international business cycle dynamics. Journal of the European Economic Association 3 (5), 966-1006.

Sussmuth, B., 2002. National and supranational business cycles (1960-2000): A multivariate description of central G7 and EUR015 NIPA aggregates. ifo Studien 48. 
Takens, F., 1981. Detecting strange attractors in turbulence. In: Dynamical Systems and Turbulence. Vol. 898 of Lecture Notes in Mathematics. Springer, Berlin, pp. 366-381.

Vautard, R., Ghil, M., 1989. Singular spectrum analysis in nonlinear dynamics, with applications to paleoclimatic time series. Physica D 35, 395-424.

Vautard, R., Yiou, P., Ghil, M., 1992. Singular-spectrum analysis: a toolkit for short, noisy chaotic signals. Physica 58, 95-126.

Von Storch, H., 1995. Inconsistencies at the interface between climate research and climate impact studies. Meteorologische Zeitschrift 4, 72-80.

Wang, P., 2013. Business cycle phases and coherence? A spectral analysis of UK sectoral output. The Manchester School 81 (6), 1012-1026.

Woitek, U., 1996. The G7-countries: A multivariate description of business cycle stylized facts. In: Barnett, W., Gandolfo, G., Hillinger, C. (Eds.), Dynamic Disequilibrium Modelling: Theory and Applications. Cambridge University Press., pp. 283-309.

Zarnowitz, V., 1985. Recent work on business cycles in historical perspective: a review of theories and evidence. Journal of Economic Literature 23 (2), $523-80$. 


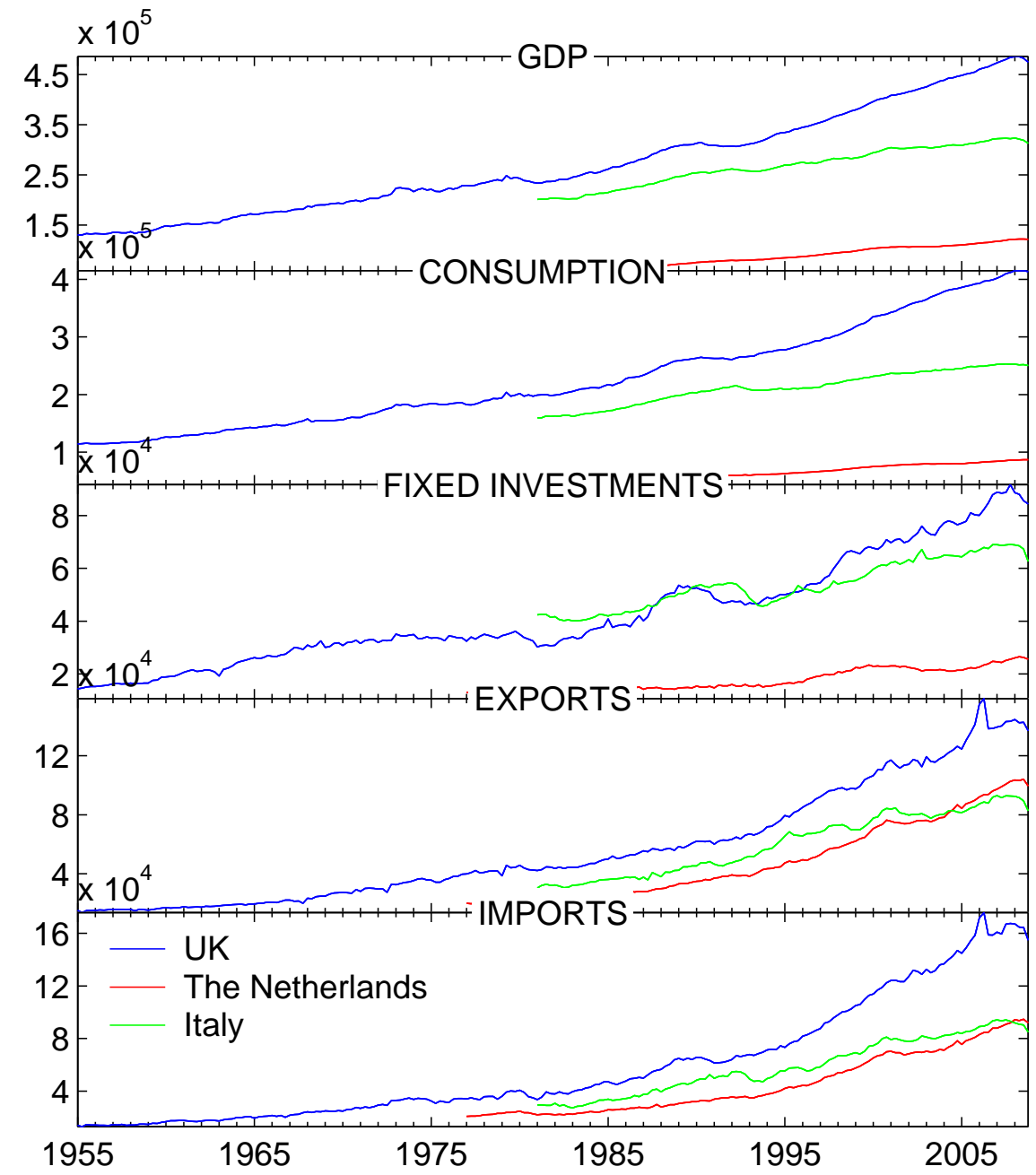

Figure 1: Time series of gross domestic product (GDP), consumption, fixed investments, exports and imports for the United Kingdom (UK, blue curve), The Netherlands (green curve), and Italy (red curve). These raw series are based on EUROSTAT data and expressed in constant, year-2000 Euros. See text and http://epp.eurostat.ec.europa.eu/ for details. 


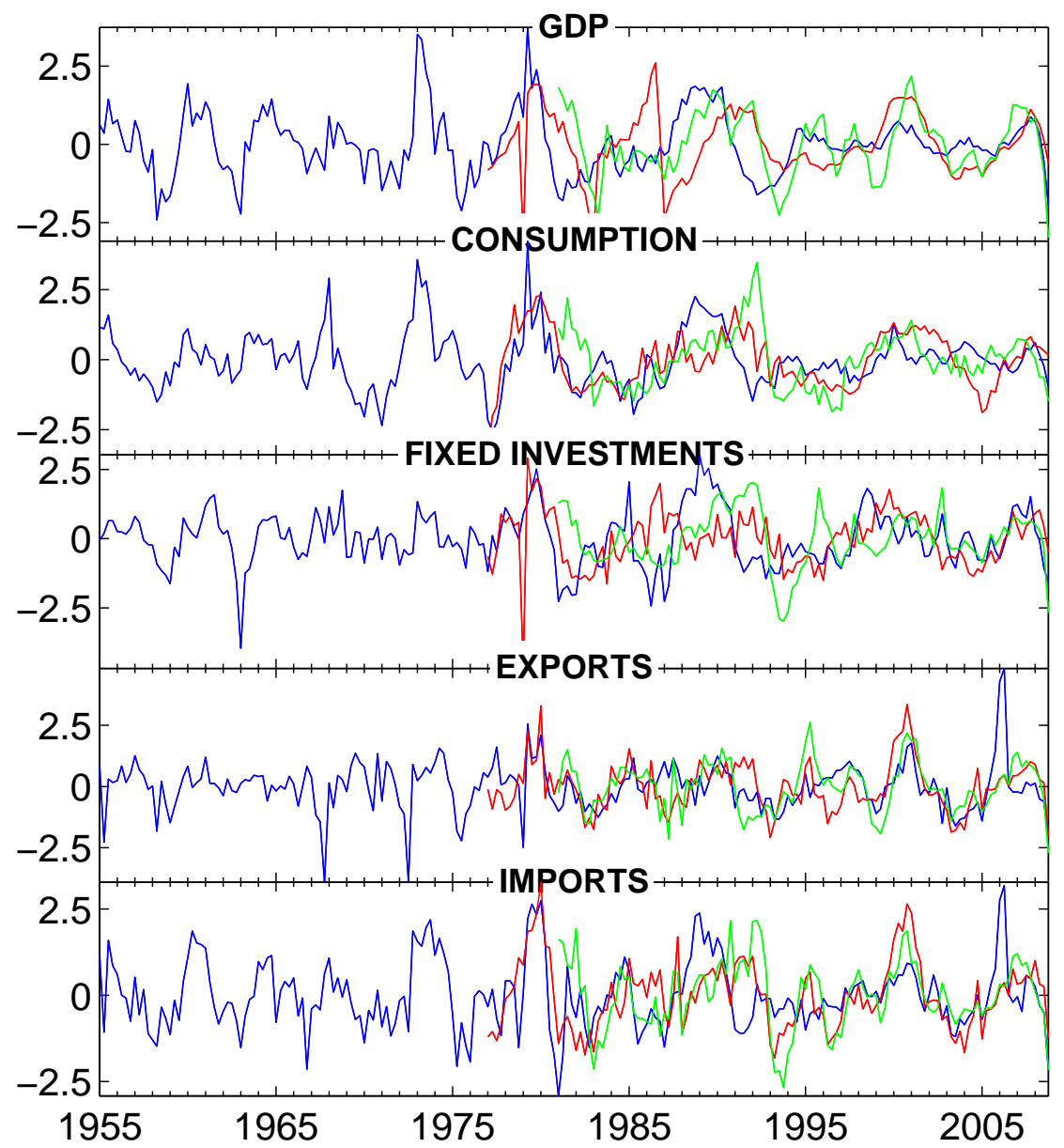

Figure 2: Same time series as in Fig. 1, but pre-processed to extract the trend and normalize the residuals so obtained. The underlying cyclical structure is visually apparent, and it is the subject of the following analysis. Same color convention as in Fig. 1 and in subsequent figures. 

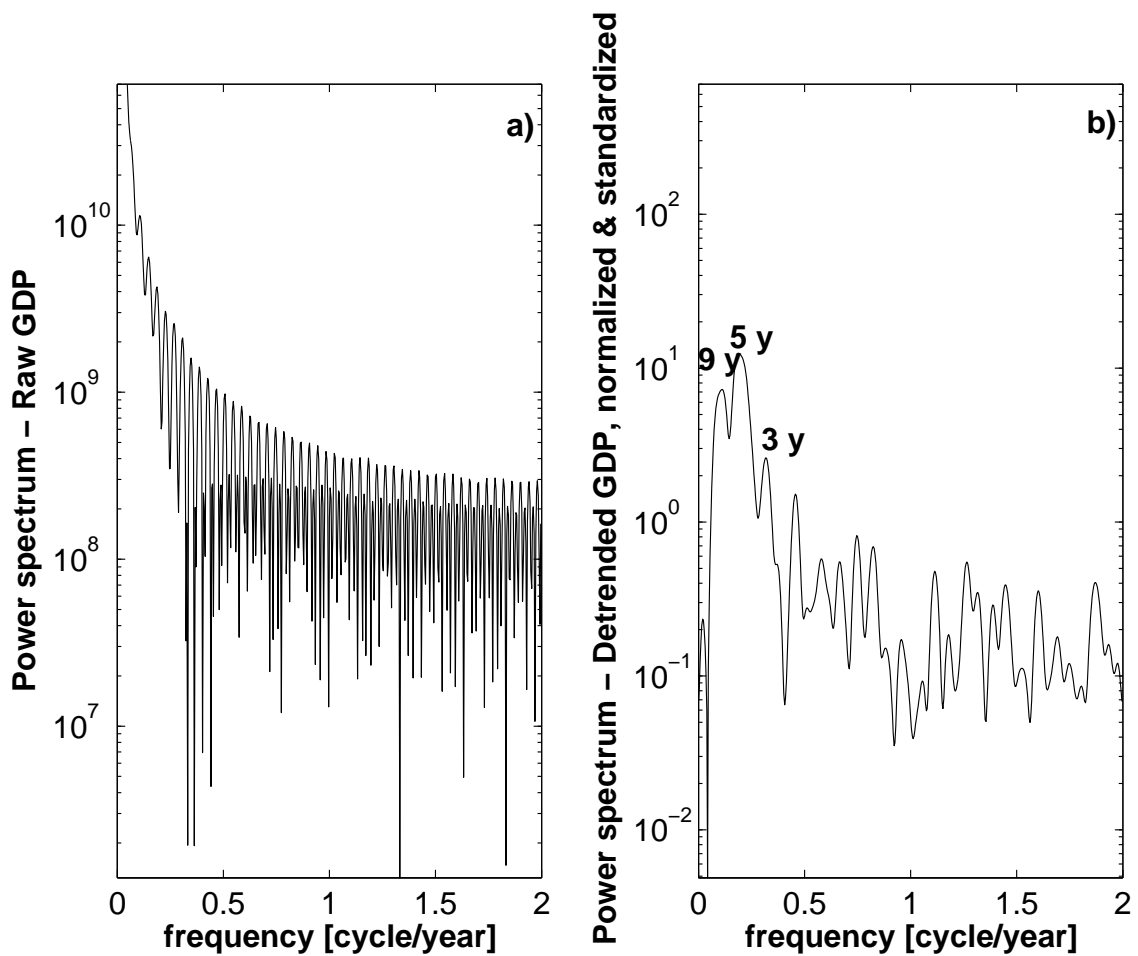

Figure 3: Power spectral density (PSD) estimate for the GDP of the UK. Panel (a) PSD estimate for the raw data; panel (b) PSD estimate for the pre-processed trend residuals. PSD estimation was carried out by the Blackman-Tuckey algorithm with a Hanning window of $M=100$ quarters (Blackman and Tukey, 1958). 


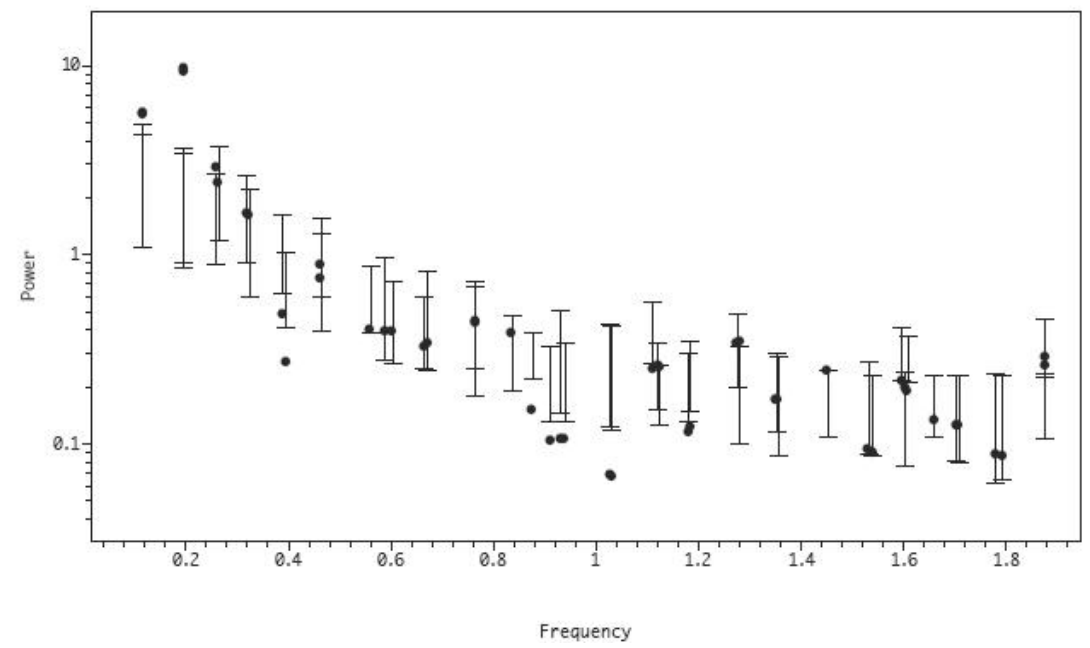

Figure 4: SSA analysis of the UK GDP: Monte Carlo singular spectrum of the transformed residual series with $M=50$. The filled circles represent the eigenvalues, while the lower and upper ticks of the error bars represent the $2.5 \%$ and $97.5 \%$ red noise percentiles. 

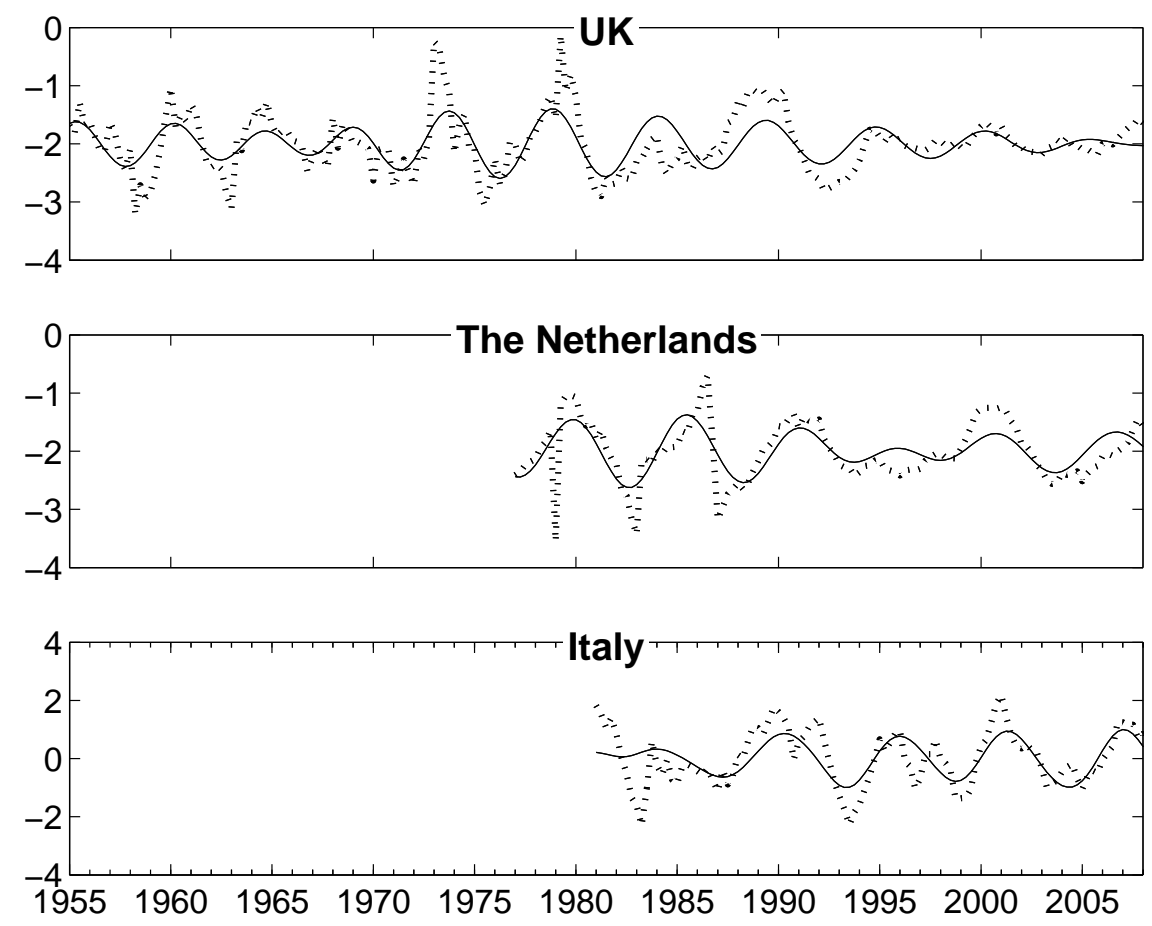

Figure 5: SSA reconstruction of the 5-year oscillation in the GDP time series of the three countries under study (solid line). This oscillation is represented by the first two eigenpairs in each series, and it captures $39 \%$ of the total variance for the UK, $44 \%$ for The Netherlands, and $40 \%$ for Italy. The window widths are $M=50,45$, and 34 quarters, respectively. The dotted curve in each panel is the same as the corresponding one in the first panel of Fig. 2. 


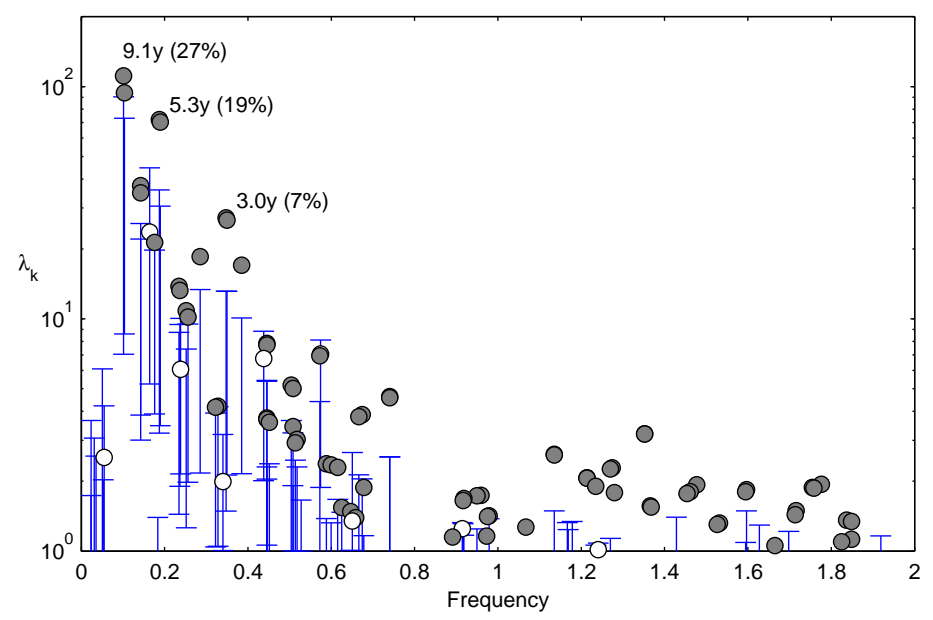

Figure 6: Eigenvalue spectrum from a global M-SSA of all 20 time series - from (4 countries) $\times$ (5 indicators) - with $M=50$. The error bars indicate the $2.5 \%$ and $97.5 \%$ percentiles of 1000 surrogate time series, while the numbers in parentheses indicate the variance captured by the pairs of eigenvalues in question. 

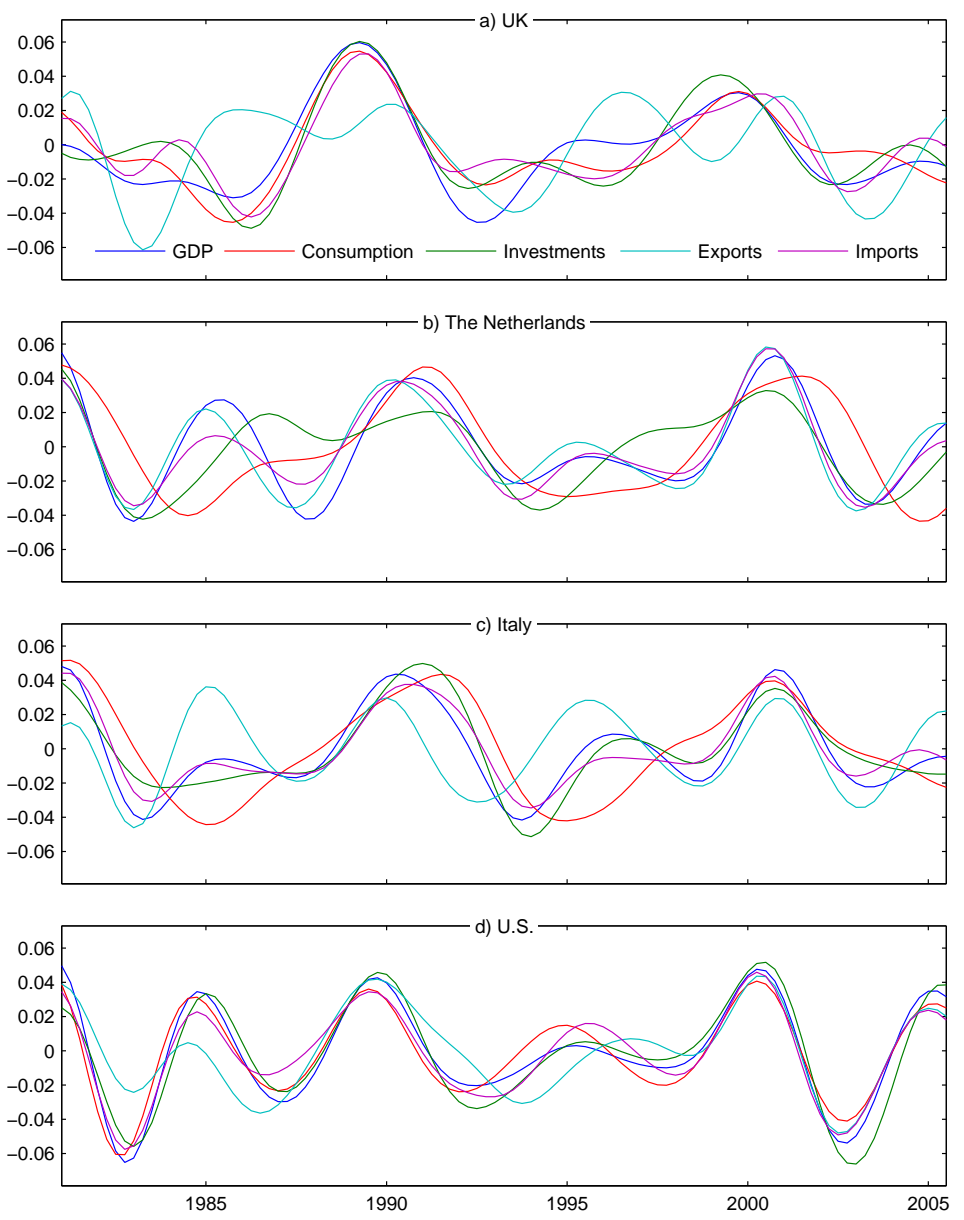

Figure 7: Further results of the global M-SSA analysis in Fig. 6 - reconstructed behavior of the 20 indicators, grouped by countries, using RCs $1-2,3-4$, and $7-8$, which belong to the three significant oscillatory pairs of period length 9,5 , and 3 years, respectively. (a) The UK, (b) The Netherlands, (c) Italy, and (d) the U.S.; indicators for each country identified by the five colors shown in the legend of panel (a). 


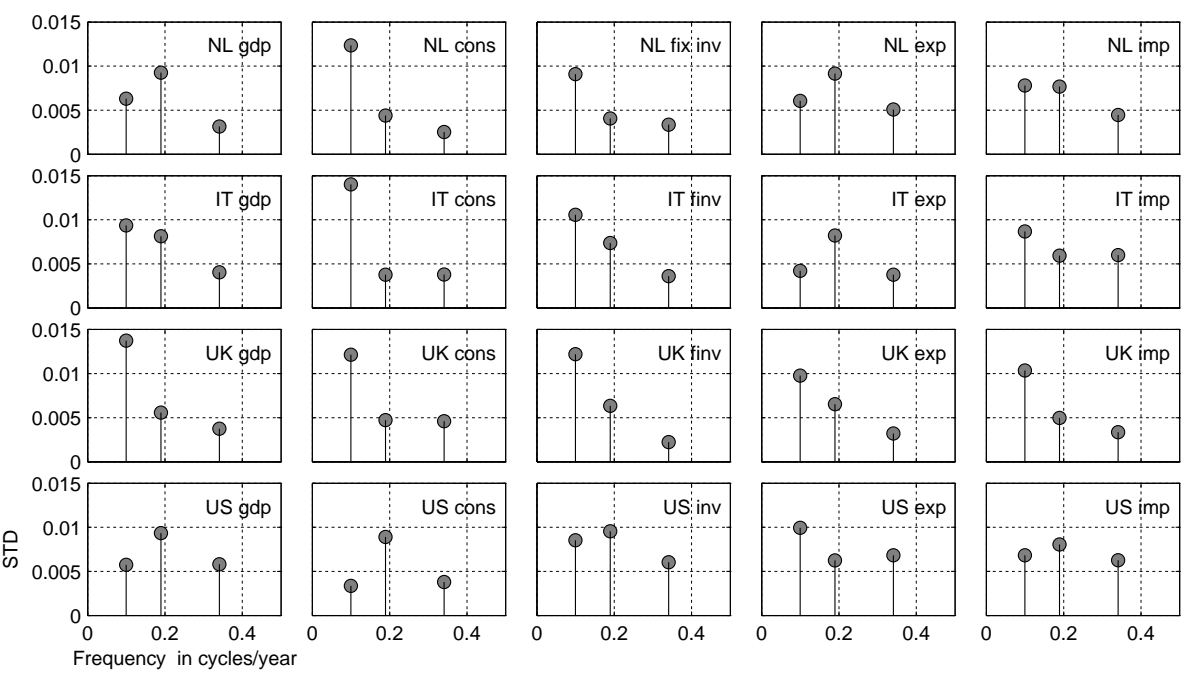

Figure 8: Standard deviation of the RCs as a measure of participation strength. The plot shows the RCs that correspond to the highly significant oscillatory pairs - namely RCs 1-2, $3-4$, and 7-8 - vs. their dominant frequency. 